\title{
Land or sea? Foraging area choice during breeding by an omnivorous gull
}

\author{
Natalie Isaksson ${ }^{1 *}$, Thomas J. Evans ${ }^{1}$, Judy Shamoun-Baranes ${ }^{2}$ and Susanne Åkesson ${ }^{1}$
}

\begin{abstract}
Background: Generalist predators may vary their diet and use of habitat according to both internal state (e.g. breeding stage) and external (e.g. weather) factors. Lesser black-backed gulls Larus fuscus (Linnaeus 1758) are dietary generalists, foraging in both terrestrial and marine habitats during breeding. We investigate what affects the gulls' propensity to forage at sea or on land. We assess the importance of terrestrial foraging to gulls in the Baltic Sea (sub. sp. L. f. fuscus), looking especially at their use of agricultural fields.

Results: Through the GPS tracking of 19 individuals across 3 years we tracked 1038 foraging trips and found that $21.2 \%$ of foraging trips were predominantly terrestrial, $9.0 \%$ were a mix of terrestrial and marine, and $68.5 \%$ were exclusively marine. Terrestrial trips were (1) more frequent when departing around sunrise, whereas marine trips occurred throughout the day. Additionally, trips with mostly land-based foraging decreased as the breeding season progressed, suggesting dietary switching coincident with the onset of chick provisioning. (2) During cloudy and cold conditions terrestrial foraging trips were more likely. (3) We found no differences between sexes in their land-based foraging strategy. (4) Gull individuals showed great variation in foraging strategy. Using observations of agricultural fields, carried out for one year, we found that (5) gulls preferentially foraged on fields with short vegetation, and there was a positive association with occurrence of waders and other species of gulls. (6) The availability and use of these preferred fields decreased through the breeding period.

Conclusions: This study found high prevalence of terrestrial foraging during early breeding as well as support for dietary switching early in the breeding season. The overall tendency for marine or terrestrial foraging was consistent within individuals, with gull identity accounting for much of the variation observed in foraging trips. Our results suggest that anthropogenic terrestrial food sources may play a role in the low breeding success of these gulls through either variation in quantity and/or quality. Finally, our study demonstrates the potential of combining data from GPS-tracking of individual animals with the 'ground-truthing' of habitat visited to elucidate the otherwise nebulous behavior of a generalist predator.
\end{abstract}

Keywords: Behavioral plasticity, Foraging ecology, Generalist foraging, GPS tracking, Ground-truthing, Habitat use, Individual repeatability, Larus fuscus, Lesser black-backed gull

\section{Background}

Generalist predators may vary their diet and use of habitat according to both internal state (e.g. breeding stage) and external (e.g. weather) factors [1, 2]. The breeding season poses particular challenges to individuals that need to balance their own energetic requirements with that of their offspring [3]. Studies that employ long-term GPS tracking of individuals [4] complemented by

\footnotetext{
* Correspondence: natalie.isaksson@biol.lu.se

${ }^{1}$ Centre for Animal Movement Research, Department of Biology, Ecology

Building, Lund University, Lund SE-223 62, Sweden

Full list of author information is available at the end of the article
}

detailed data on foraging site conditions [5] have the potential to elucidate factors contributing to breeding success and survival of long-lived species.

Larus gulls are an example of generalist predators with omnivorous diet which typically make use of both marine and terrestrial habitats [6,7]. As generalists, gulls may be expected to use a variety of different food sources throughout the breeding season in order to maximize fitness, depending on physiological requirements, food availability and predictability, energetic costs, and inter- or intra-specific competition. The lesser black-backed gull Larus fuscus (Linnaeus 1758) of which the nominate sub- 
species (L. fuscus fuscus) was studied here, uses mostly marine food sources during breeding $[8,9]$, which they are thought to rely more on than other subspecies ( $L . f$. graeslii, L. f. intermedius) [10]. At the Karlsö islands (Fig. 1), the largest breeding site of regionally endangered L. f. fuscus in the Baltic Sea $[11,12]$, foraging on agricultural fields is expected to be common during breeding as terrestrial prey items were observed during an earlier study at the colony [13]. Gulls in general are increasingly using anthropogenic food sources including fisheries discards, refuse dumps, and agricultural land [14, 15]. Stable isotope analysis of feathers from gulls in one area taken over several decades suggested increasing reliance on terrestrial food sources likely due to declining fish abundance [16]. In the Baltic Sea cod stocks have plummeted while sprat and herring stocks have increased leading to an ecological regime shift [17]. Though sprat and herring numbers are high, their quality is reduced as a result of density-dependent food competition [18], with potential consequences for breeding seabirds [19]. Agricultural fields are a relatively new food source in the area and could be exploited in the face of declining quantity or quality of previous (more marine) food sources. However, it is not currently well understood how such novel anthropogenic food sources influence foraging patterns and how they may affect population viability in the long term.

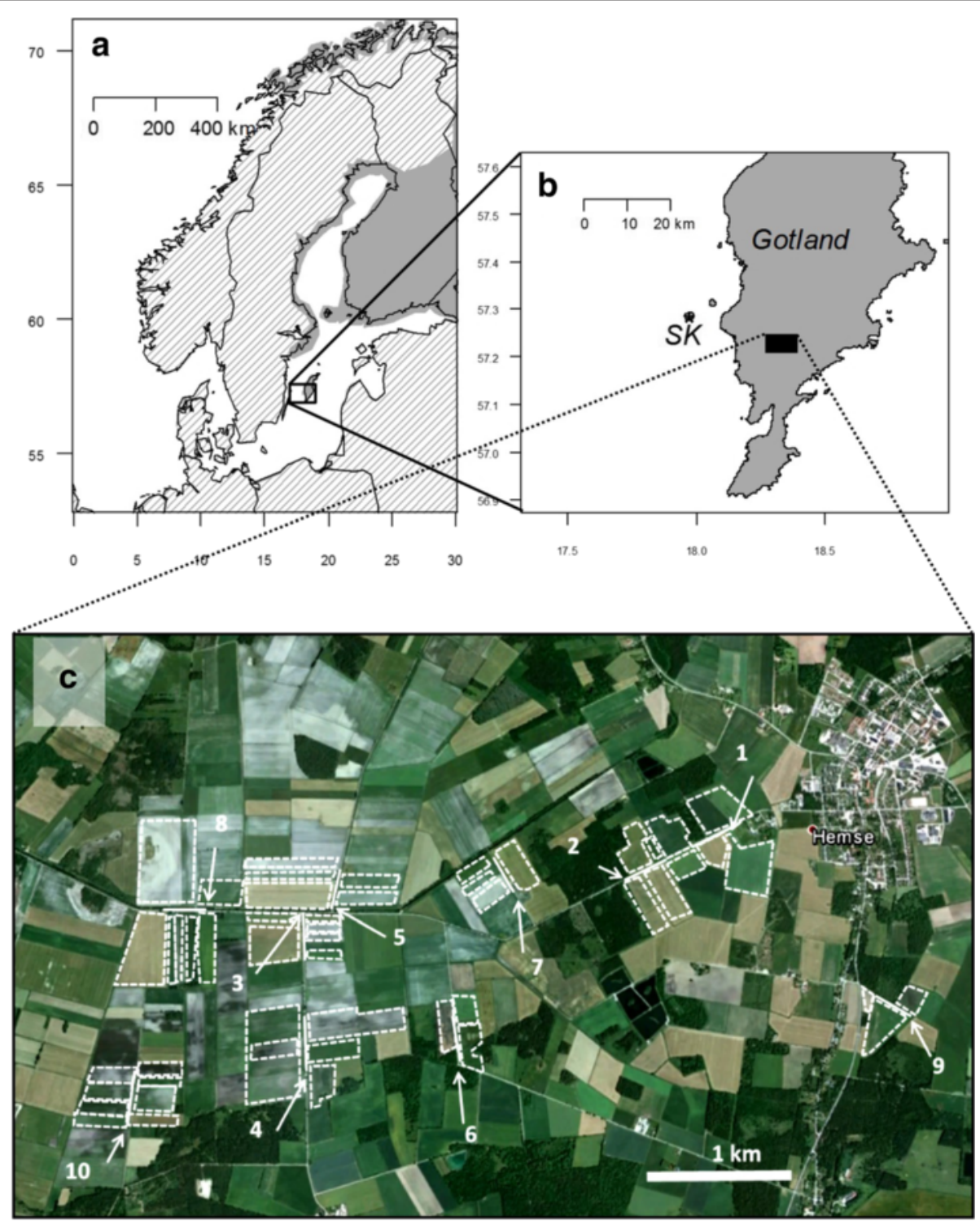

Fig. 1 Study area map. Maps showing; (a) breeding range of the nominate lesser black-backed gull sub-species (Larus f. fuscus), grey uniform fill, after [71]. b Expansion showing colony location (SK*), and location of study fields (black filled rectangle). $\mathbf{c}$ Location of field transects (white lines) with arrows marking start position (precise location in supplementary table 2) and the bordering fields included in the study indicated (outlined by dashed white lines) (Map data: Google, Lantmäteriet/Metria) 
During breeding, gulls are central-place foragers, sensitive to the availability of prey in both space and time and modulate their foraging behavior accordingly [6, 20, 21]. Therefore, we can expect lesser black-backed gulls to vary their use of land and sea foraging habitats across the course of a day and between years, depending on the availability of prey. Previous studies on lesser black-backed gulls suggest dietary switching, from terrestrial to marine food sources occurs in conjunction with changing breeding stage, from incubation to chick-rearing [22-24]. During incubation, breeding adults may be selecting for food that is more predictable in time and space as opposed to of high quality [22]. Later in the season, chicks may require high-energy and easily digestible food items, which are more likely to be provided by marine fish than terrestrial invertebrates [15, 23-25]. We may therefore expect gulls at our colony to display similar dietary switching behavior during the course of the breeding season.

Records of foraging on agricultural land by gulls show that earthworms (Lumbricidae) and insects (Insecta) are frequent prey items $[26,27]$. These prey are more available under rainy conditions [28], increasing the likelihood of gulls using agricultural fields during cloudy and wet weather. As gulls forage by sight and walk with an upright posture; agricultural fields with short sparse vegetation and fields with crops having these characteristics are likely to be targeted when foraging on land [29]. The availability of these types of fields will both determine field selection by terrestrially foraging gulls, and as field conditions change through the breeding season, the propensity of gulls to choose to forage on land or at sea.

Finally, recent studies suggest individual and sex differences in foraging behavior [7], with these differences potentially arising from sex specific nutritional requirements such as for females during egg-production [30] or from risk partitioning [31]. It can therefore be hypothesized that female lesser black-backed gulls would forage more on land than males and that individuals may show a propensity for one or the other foraging strategy.

In our study we used a combination of GPS tracking during three breeding seasons (2011-2013), and observations on agricultural land during one breeding season (2013) to characterize lesser black-backed gull foraging behavior. We investigated how gulls chose between terrestrial or marine foraging trips, and what factors affected this decision. As agricultural fields are the only significant terrestrial food source for the gulls in this area with limited refuse dump availability [13], we looked at what kinds of agricultural fields gulls use during terrestrial foraging. Specifically we focused on the following questions: (1) how the gulls vary their propensity for terrestrial or marine foraging trips over time, from time of day, across the breeding season, and among years; (2) how weather affects their foraging decisions,
(3) whether sexes differ in their foraging behavior, (4) whether individuals are consistent in foraging strategy, (5) what the characteristics are of the agricultural fields that they forage on including any potential association with other foraging bird species, (6) and how the availability of these suitable agricultural fields changes through the breeding period.

\section{Methods}

The study was carried out at Stora Karlsö, Gotland, Sweden $\left(57^{\circ} 17^{\prime} \mathrm{N}, 17^{\circ} 58^{\prime} \mathrm{E}\right)$, a small island $\left(2.5 \mathrm{~km}^{2}\right)$ in the western Baltic Sea, located $7 \mathrm{~km}$ to the west of Gotland (Fig. 1), a large island $\left(>3,000 \mathrm{~km}^{2}\right)$ with mixed landuse, including forestry and arable agriculture. Stora Karlsö has major seabird breeding populations of common murre Uria aalge, razorbill Alca torda, great cormorant Phalacrocorax carbo, herring gull Larus argentatus, arctic tern Sterna paradisaea, and lesser black-backed gull (ca. 500 pairs), with smaller populations of other species [32]. Locally, numbers of the eastern breeding nominate subspecies, L. f. fuscus, have been declining [11]. On a national level the species has an IUCN regional Red List categorization of endangered [12].

\section{GPS tracking}

During incubation in late May and early June of 20112013 we deployed 18 g solar-powered GPS devices with remote-download capability (UvA-BiTS, University of Amsterdam, The Netherlands) [33] on 21 breeding lesser black-backed gulls (see Additional file 1). Devices were attached using harnesses constructed of tubular Teflon ${ }^{\mathrm{TM}}$ ribbon (Bally Ribbon Mills 8476-.25") with a $1 \mathrm{~mm}$ braided nylon wader shelf string (British Trust for Ornithology) inserted, either with a wing- (2011) or full body- harness (2012, 2013) (see [34] for description of harness types). Attachment method changed between years in order to improve re-capture rates, however we recommend the wing harness following [34]. The combined weight of the GPS device plus harness was ca. 21 g, corresponding to a mean of $2.9 \%$ (range 2.3 $3.6 \%$ ) of body mass at time of deployment. GPS tracking was continuous with location intervals typically of 300 or $600 \mathrm{~s}$, though with some gaps following prolonged overcast conditions. Data were downloaded and programs uploaded to the GPS devices when the gulls were present at the breeding colony, where a network of 2-4 antennas provided good coverage of the breeding area. Birds were sexed morphologically by head plus bill measurements according to [35], with a colony-specific discriminant threshold of $113.5 \mathrm{~mm}$ (< female, > males).

Foraging trips during the breeding season (May-July) were analyzed, focusing on colony-wide breeding stages of 20 days each: incubation (May 20-June 9), early chickrearing (June 10-30) and late chick-rearing (July 1-21). 
Pre-laying stage (April 30- May 19) data from 2012-13 were used in further analyses of most competitive models, in order to minimize the effect of lack of data from 2011. GPS point data were segmented by setting a distance threshold $(500 \mathrm{~m})$ around each gull's nest, defining the start $(>500 \mathrm{~m})$ and end of trips $(<500 \mathrm{~m})$. Trips were filtered to include only normal breeding period foraging trips ('long trips' in [7]) with adequate GPS tracking data for analysis (see Additional file 2).

To analyze the tendency of gulls to use land or sea habitat during the GPS tracked foraging trips, we classified the proportion of foraging time spent on land (for full details see Additional file 2). To do this, within foraging trips, likely foraging GPS locations were extracted for each trip using two speed thresholds and a minimum distance of $3 \mathrm{~km}$ from the colony. Then these foraging locations were classified as either on land or at sea. Finally for our response variable for statistical analyses, for each trip we calculated the proportion of foraging locations on land rather than sea, a value between 0 (all foraging locations at sea) and 1 (all foraging locations on land). The foraging trip data were further annotated with weather information, departure time relative to sunrise time, breeding stage (see above), year (2011, 2012, 2013), and with the proportion of terrestrial and marine foraging (see below for more details). Weather data were extracted and summarized for the colony location (Stora Karlsö) for the $24 \mathrm{~h}$ period up to the departure time of each foraging trip (see Additional file 3). These were extracted from 'NCEP-DOE Reanalysis 2' [36] using R [37] package RNCEP [38]. The variables extracted were: precipitation rate, air temperature at $2 \mathrm{~m}$, east and north wind vectors at $10 \mathrm{~m}$, total cloud cover (RNCEP variable names, respectively: prate.sfc, air. $2 \mathrm{~m}$, uwnd.10 $\mathrm{m}$, vwnd.10 $\mathrm{m}$ and $t c d c . e a t m$ ), which were linearly interpolated to the colony location and time points: (relative to departure time $\left.t_{d e p}\right) t_{d e p}, t_{d e p}-6 h, t_{d e p}-12 h, t_{d e p}-18 h$. Mean values were then calculated from the 4 time points for all variables except precipitation rate, where the sum was taken (representing cumulative rainfall during $24 \mathrm{~h}$ preceding trip departure time). We analyzed wind speed in both N-S and E-W components, with E-W corresponding approximately to head/tail winds when travelling to and from Gotland, and N-S to side-winds if travelling to/from Gotland. We calculated a variable 'sunrise proximity', to indicate how close to sunrise a trip departure occurred. Sunrise times for the day of each foraging trip were extracted with function sunriset in $\mathrm{R}$ package maptools [39] this was then transformed by taking the cosine of time-since-sunrise divided by 12 and multiplied by $\pi$, i.e. $\cos (\pi *$ time-since-sunrise/12) following a similar calculation by [40]. This provided a value between 1 and -1 , with values at: sunrise, $1 ; 6 \mathrm{~h}$ from sunrise, 0 ; and $12 \mathrm{~h},-1$. The proportion of foraging time spent on land (see Additional file 2 for details) was used as the response variable (see Statistical Analysis below). For illustration this was put into three classes: sea $(<5 \%$ foraging time on land), mixed (5-95\% foraging time on land), and land (>95\% foraging time on land).

\section{Agricultural fields}

A ca $28 \mathrm{~km}^{2}$ agricultural area in south-west Gotland with representative fields of the region was selected as a field site (Fig. 1 b). Site selection was based on the activity of GPS-tagged lesser black-backed gulls in the period just prior to the study period (late May 2013). Within this area we plotted ten transects along roadways, each of $300 \mathrm{~m}$ in length (Fig. $1 \mathrm{c}$ ). Transects were selected to include at least one field visited by a GPS tracked gull, plus at least one control field where gulls had not been recorded. Fields bordering each transect were surveyed giving a total of 50 fields (see Additional file 4). Of these, seven fields were visited by two GPS-tagged individuals (individuals 8114314 and 8111250) during the study period. Fields were surveyed during June and early July 2013, representing late incubation or early chick-rearing through to middle-late chick-rearing in our colony of lesser black-backed gulls (pers. obs.). Fields were visited during three 6-day periods: 13-18 June, 24-29 June, and 3-8 July. During each period we observed in the morning (04:00-10:00 $\mathrm{h}$, days $1-3)$ and evening (16:0022:00 h, days 4-6). Over a twenty minute period at each field we counted the maximum numbers of the following species present: black-headed gull, common gull $L$. canus (Linnaeus 1758), herring gull, lesser black-backed gull, lapwing Vanellus vanellus (Linnaeus 1758), and oystercatcher Haematopus ostralegus (Linnaeus 1758). As we were interested in general characteristics of fields typically used and those seemingly avoided by gulls, we did not make a distinction between age classes or behaviors in our observations but noted presence or absence. In our observations birds regularly fed with bouts of foraging (e.g. active searching for prey where they were walking with head down) interspersed with resting. Thus it was likely that presence on a field was a strong indication that the bird was present for foraging, even if active foraging was not observed within the twenty minute observation period. Earthworm availability on the fields was also assessed. We walked along a 4x25 m gate transect at a speed of one footstep per second and counted how many earthworms were seen within a $1 \mathrm{~m}$ perimeter, similar to the method described in [41].

To assess the vegetation characteristics of the fields and how these changed through the season we surveyed each field during each of the three observation periods, visiting during non-observation hours (i.e. 10:00-16:00). To account for variation within fields we placed five quadrats $(1 \mathrm{x} 1 \mathrm{~m})$ each $3 \mathrm{~m}$ from the field border 
ensuring that at least three of the four or more sides of fields were covered. For further analysis we took the mean for each field and period of vegetation height and percentage vegetation cover (consequently ranked into 4 classes: 0-25 \%, 25-50 \%, 50-75 \%, and 75-100 \%). During field visits the crop plants grown in fields were identified. We pooled crops into 5 crop types: cereal (barley, oats, wheat), grass (grasses), roots (carrots, potato), ryegrass, and other (rapeseed, snow pea).

\section{Statistical analyses}

Two sets of statistical analyses were made to look at the foraging activity by the lesser black-backed gulls, first on their use of terrestrial over marine foraging within GPS tracked foraging trips and secondly to look at what fields were used by gulls and when. For the GPS tracked foraging trip analysis the proportion of terrestrial foraging during each trip was the response variable. For the field observation analysis, the presence/absence of lesser black-backed gulls was the binomial response variable. This binomial variable was chosen as very few lesser black-backed gulls were observed during the field observations thus these observations were reduced to presence or absence. In order to model the probability of marine or terrestrial foraging during trips we constructed a priori logistic mixed effects models with individual gull identity included as the random effect. Field observations included field ID nested within transect ID as a random effect. Generalized linear mixed models (GLMMs) were built with the package lme4 [42] in R, using the glmer() call and specifying family as binomial and link as logit. Final models were selected based on lowest corrected Akaike Information Criterion (AICc) values [43]. The proportion of total variance explained by fixed effects in models was assessed using marginal $\mathrm{R}^{2}$ values, and that explained by the combined fixed and random effects by conditional $\mathrm{R}^{2}$ values [44] extracted with the $R$ package $M u M I n$ [45]. The most competitive models for GPS tracked foraging trips were re-run with the dataset including data from the pre-laying period in 2012-2013. In the final selected models we tested for variable significance by dropping single terms then comparing these to the full model via likelihood ratio tests. The final model was standardized [46] using the R package arm [47] and assessed for collinearity, with a kappa value of less than 10 considered acceptable [48].

We quantified how consistent the GPS tracked gulls were in their tendency to use terrestrial or marine habitat during foraging trips by calculating repeatability $(r)$, as the proportion of the total variance in the response variable (i.e. proportion of foraging locations with each trip spent on land rather than at sea) accounted for by differences between individuals rather than within individuals. The result was a value between 0 (all variation is within rather than between individuals) and 1 (all variation is explained by differences between individuals) [49]. We obtained $r$ for the standardized best fit model (thus repeatability once main effects are accounted for) and calculated a $\mathrm{p}$ value by randomization and the $95 \%$ confidence intervals from a parametric bootstrap, both with 1000 iterations (following method of [49] as outlined in [50]).

\section{Results}

\section{GPS tracking}

We obtained GPS tracking data for 21 lesser black-backed gulls during the period 2011-2013 (see Additional file 1). However, for one individual the device failed, and the other abandoned breeding shortly after capture, thus both individuals were excluded from further analyses. This resulted in a dataset of 1038 foraging trips (examples in Fig. 2 and overall distribution given in Additional file 5) from 19 individuals (see Additional file 3) for the focal period (20th May - 21st July). Of these foraging trips 220 (21.2\%) consisted entirely of terrestrial foraging, 93 $(9.0 \%)$ were a mix of terrestrial and marine foraging, and $711(68.5 \%)$ were exclusively marine foraging (14 trips were unclassified, see Additional file 2). Foraging trips had a median duration of $4.8 \mathrm{~h}$ (IQR 2.6-8.6) with median maximum distance of $22.3 \mathrm{~km}$ (IQR 15.3-37.5) from the colony, though with considerable variation (see also, Additional file 2: Figure S1 and Figure S2 respectively, and Additional file 5). These parameters also varied between trip types, with median durations of $6.2 \mathrm{~h}$ (IQR 4.1-9.8), $3.9 \mathrm{~h}$ (IQR 2.2-6.8), and $11.3 \mathrm{~h}$ (IQR 8.1-15.0) for land, sea, and mixed trips respectively. Median maximum distances were $20.8 \mathrm{~km}$ (IQR 17.4-22.7), $23.2 \mathrm{~km}$ (IQR 13.241.1), and $39.3 \mathrm{~km}$ (IQR 22.6-49.3) for land, sea, and mixed trips respectively.

The propensity for lesser black-backed gulls to use terrestrial rather than marine habitat during foraging trips was most affected by trip departure time relative to sunrise time, cloud cover and temperature (d.f. $=3, x^{2}=$ 289.8, model 18 in Table 1, Fig. 3a). Terrestrial foraging predominated on foraging trips departing soon before or after sunrise (Fig. 4 b, $\chi 2=213.9, p<0.001$ ). Weather also affected the propensity for terrestrial foraging, with greater cloud cover $(\chi 2=15.2, p<0.001)$ and lower temperatures $(\chi 2=56.4, p<0.01)$ increasing the likelihood. There was no difference between male and female gulls in their tendency to perform terrestrial foraging trips, with models containing sex having higher AICc (e.g. models 8-10 in Table 1, Additional file 6). However, we did find that including individual differences greatly improved the model fit, with individual included as a random effect leading to a high conditional $R^{2}$ (0.698), much higher than the marginal (main effects) $R^{2}(0.280)$. This was further corroborated by analysis of individual 


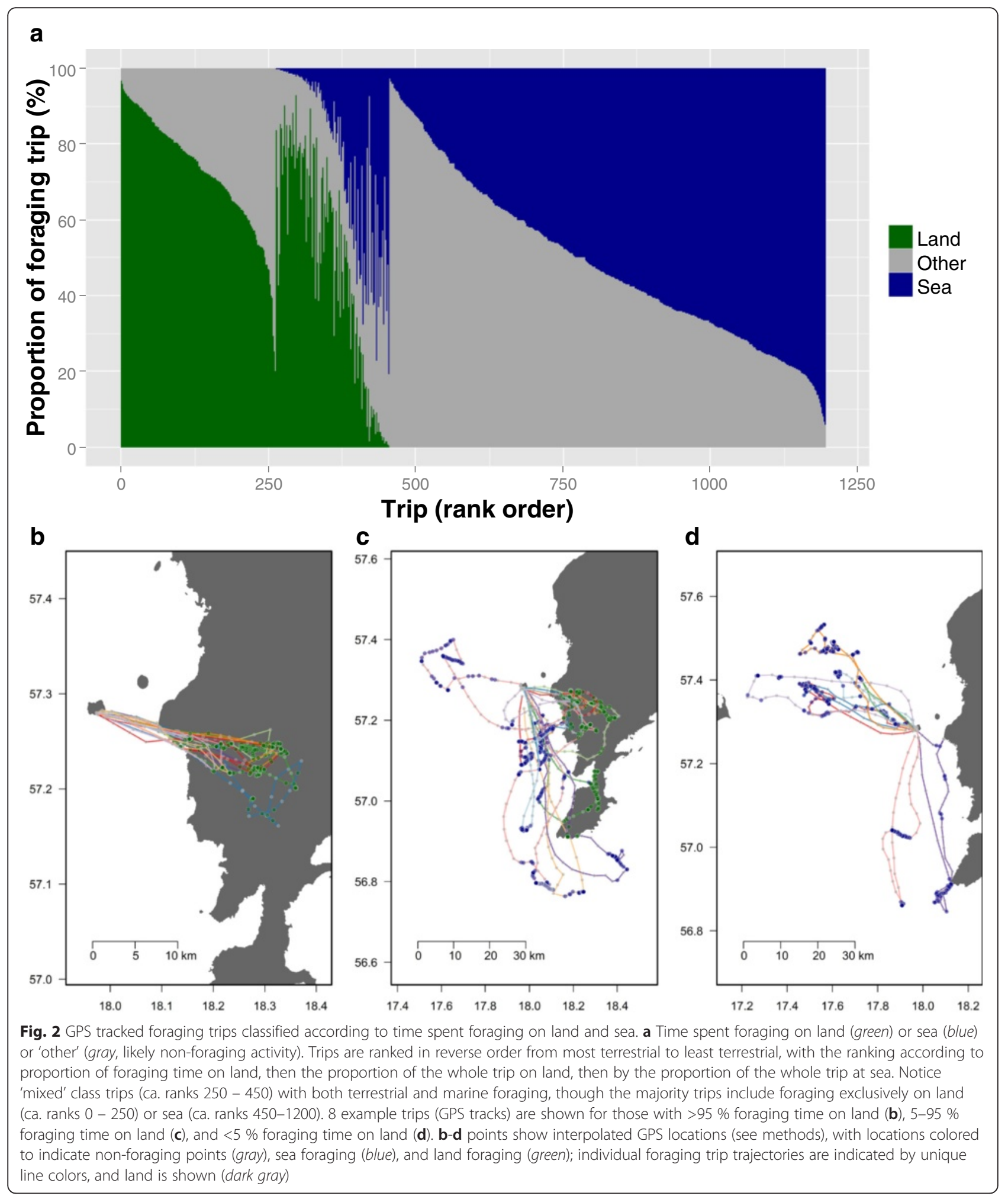

repeatability, which was significant and very high $(r=$ $0.814, p<0.001,95 \% \mathrm{CI}=0.612-0.891)$.

The most competitive models (15-18 in Table 1$)$, with $\triangle \mathrm{AICc}<2$, were re-run with the dataset from 2012-
2013 that also included data on the pre-laying period (April 30-May 20). The final model (model 6 in Table 2, $\kappa=5.79$ ) was selected based both on AICc value and a threshold of $\kappa<10$, with the addition of temperature 
Table 1 Summary statistics for GLMMs to look at temporal and weather influences on the probability of lesser black-backed gulls $(n=19)$ to forage on terrestrial- over marine- habitat during foraging trips $(n=1024)$. All models include individual gull ID as a random effect. Akaike information criterion adjusted for small sample sizes (AICc), change in AICc relative to the best-fit model (18) and marginal $R^{2}\left(R^{2} m\right)$ and conditional $R^{2}\left(R^{2} c\right)$ values are presented

\begin{tabular}{|c|c|c|c|c|c|c|}
\hline & Model & d.f. & $\mathrm{AlCc}$ & $\triangle \mathrm{AICC}$ & $R^{2} m$ & $R^{2} C$ \\
\hline 1 & intercept & 2 & 974.6 & 283.8 & - & 0.472 \\
\hline 2 & cloud + temp & 4 & 902.7 & 211.9 & 0.086 & 0.503 \\
\hline 3 & cloud + temp + ppt & 5 & 899.1 & 208.2 & 0.093 & 0.509 \\
\hline 4 & stage + cloud + temp + ppt + temp*stage & 9 & 893.6 & 202.7 & 0.119 & 0.506 \\
\hline 5 & stage + cloud + temp + ppt & 7 & 891.0 & 200.2 & 0.118 & 0.509 \\
\hline 6 & sunrise_prox & 3 & 753.2 & 62.35 & 0.195 & 0.670 \\
\hline 7 & stage + sunrise_prox & 5 & 713.9 & 23.07 & 0.265 & 0.672 \\
\hline 8 & stage + cloud + temp + ppt + sunrise_prox + year + windNS + windEW + sex + temp*stage + windNS* windEW & 16 & 704.1 & 13.27 & 0.297 & 0.692 \\
\hline 9 & stage + cloud + temp + ppt + sunrise_prox + year + windNS + windEW + sex + temp*stage & 15 & 702.1 & 11.20 & 0.291 & 0.702 \\
\hline 10 & stage + cloud + temp + ppt + sunrise_prox + year + windNS + windEW + sex & 13 & 699.5 & 8.593 & 0.285 & 0.704 \\
\hline 11 & stage + cloud + temp + ppt + sunrise_prox + year + windNS + windEW & 12 & 697.4 & 6.566 & 0.289 & 0.703 \\
\hline 12 & stage + cloud + temp + ppt + sunrise_prox + year + temp*stage & 12 & 697.1 & 6.226 & 0.284 & 0.697 \\
\hline 13 & stage + cloud + temp + ppt + sunrise_prox + year & 10 & 694.5 & 3.655 & 0.284 & 0.702 \\
\hline 14 & stage + cloud + temp + ppt + sunrise_prox + temp*stage & 10 & 694.1 & 3.233 & 0.298 & 0.693 \\
\hline 15 & stage + cloud + temp + ppt + sunrise_prox & 8 & 692.1 & 1.236 & 0.292 & 0.697 \\
\hline 16 & cloud + temp + ppt + sunrise_prox & 6 & 691.4 & 0.573 & 0.282 & 0.699 \\
\hline 17 & stage + cloud + temp + sunrise_prox & 7 & 691.4 & 0.554 & 0.290 & 0.695 \\
\hline 18 & cloud + temp + sunrise_prox & 5 & 690.9 & 0.000 & 0.280 & 0.698 \\
\hline
\end{tabular}

cloud = cloud cover(\%); ppt = precipitation, stage = incubation, early chick-rearing, late chick-rearing; sex = individual sex (female, male); temp = air temperature; sunrise_prox = proximity to sunrise; year = year $(2011,2012,2013)$; windNS = wind vector in North-south direction; windEW = wind vector in East-west direction Selected model (18) is indicated in bold

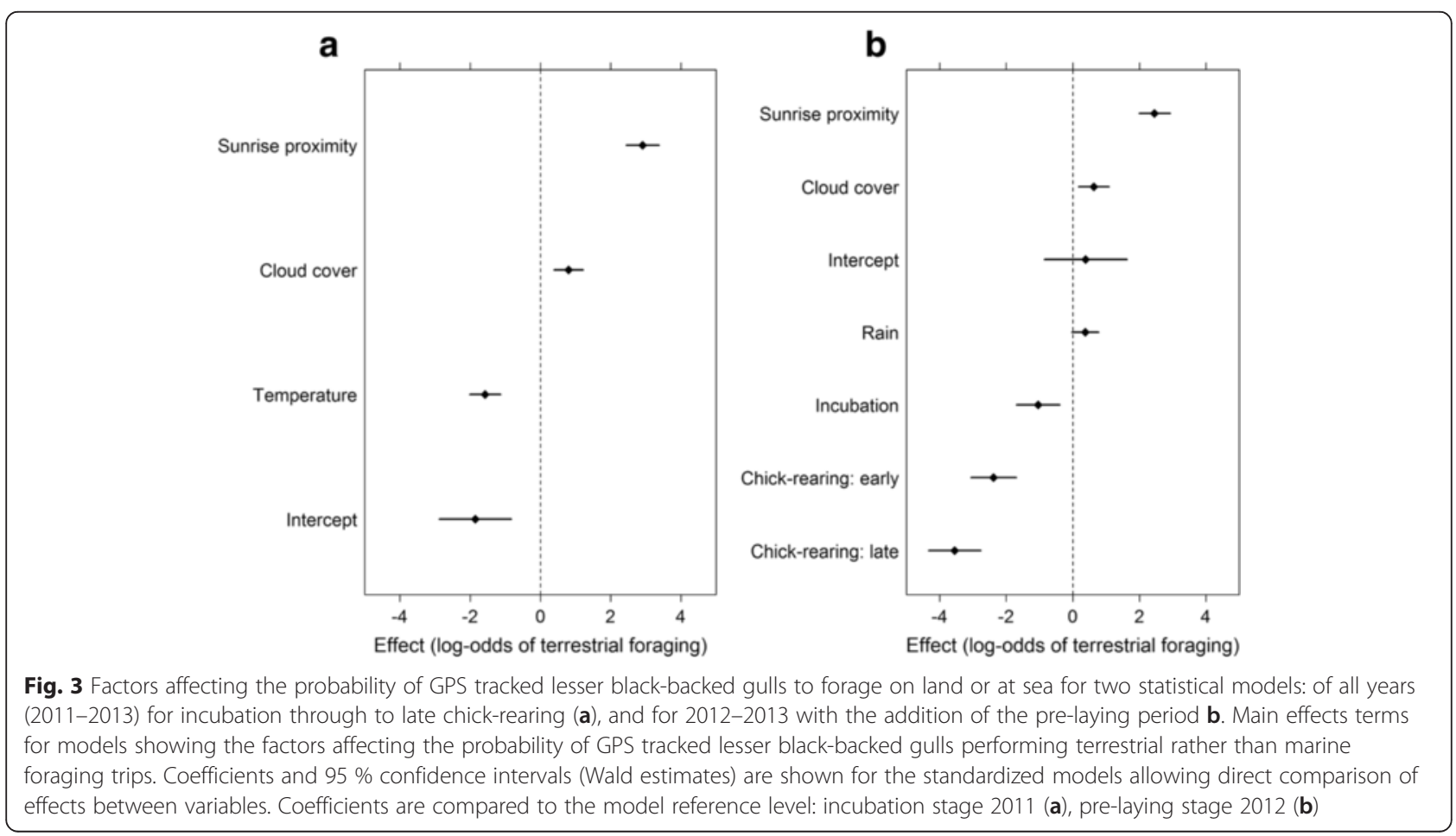




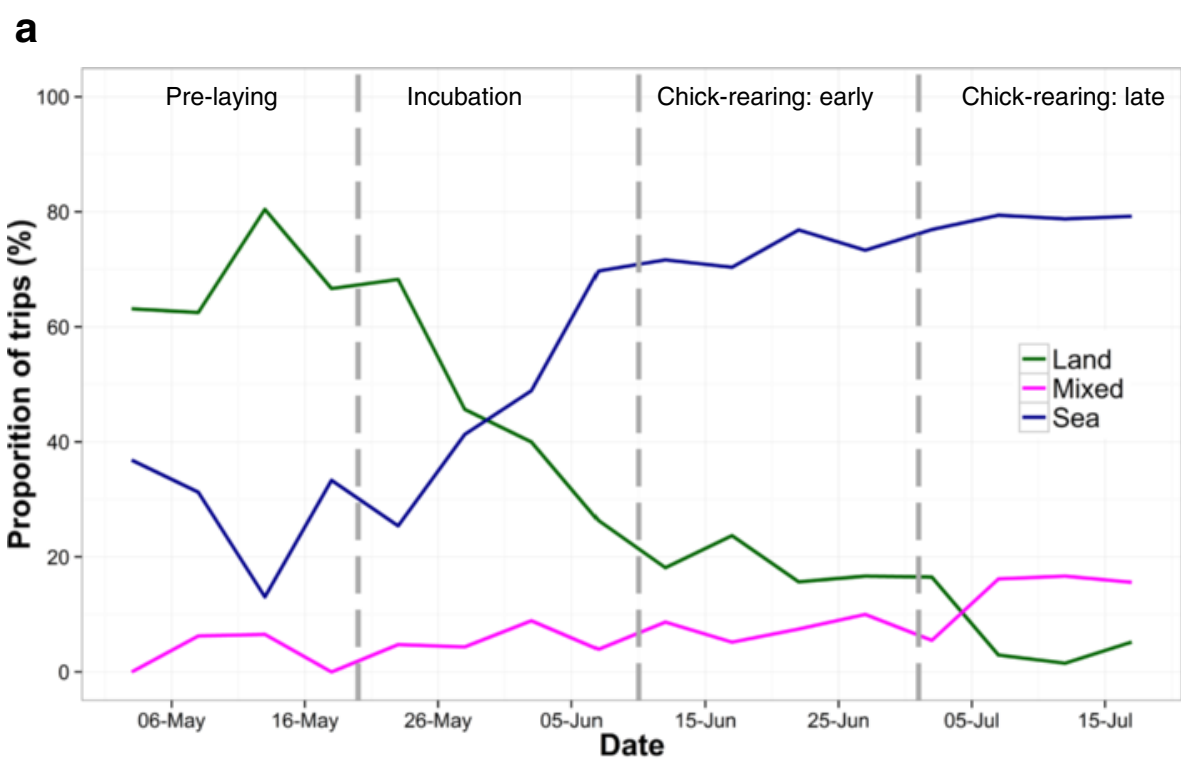

b

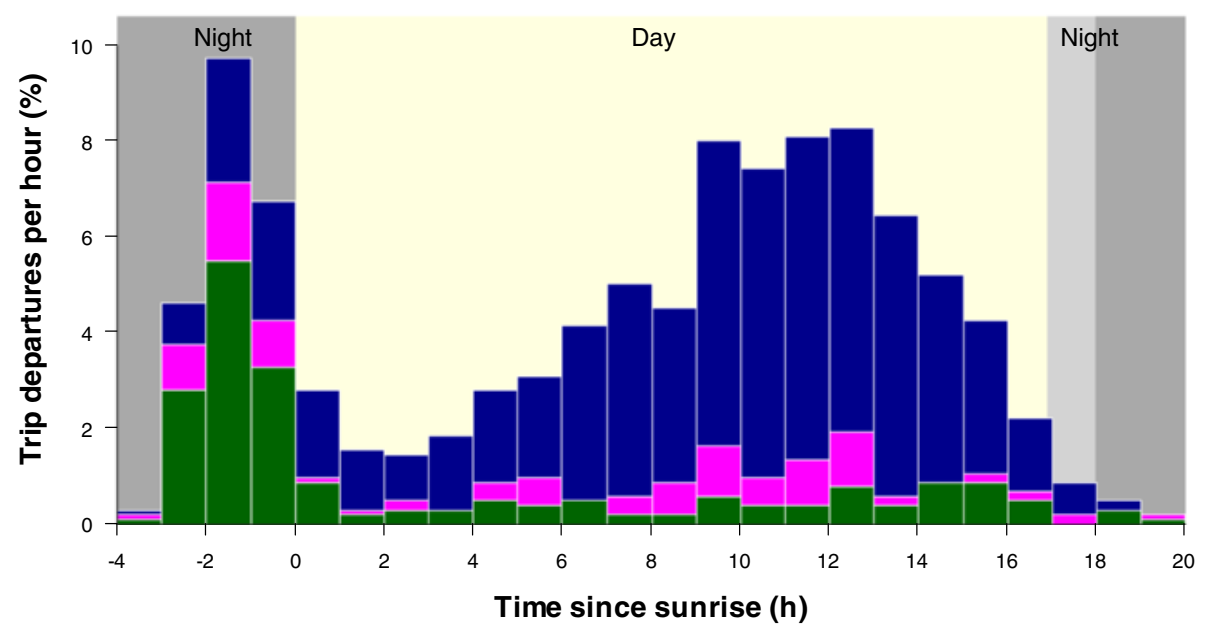

Fig. 4 The proportion of foraging trips by GPS tracked gulls classified as land, sea, or mixed for the breeding period (a) and per hour based on time of departure (b). a For each 5 day period from all 3 years pooled (also see Additional file 8 where years are separated). The breeding stages are indicated (vertical broken grey lines). Note that the pre-laying period was calculated from 2012 \& 2013 only as data for 2011 were unavailable. b Proportion of all foraging trip departures occurring each hour relative to time of sunrise performed by the gulls with data pooled for all breeding stages and years. Trip types are indicated (following same colors as panel a). Period of day is indicated, with night (dark grey), and day (light yellow); as the length of night was not constant throughout the study the maximum- (light grey) and minimum- (dark grey) night duration are indicated

(model 7 in Table 2) slightly reducing AICc but leading to an unacceptable increase in model collinearity $(\kappa=$ 14.4). Here, the propensity for lesser black-backed gulls to use terrestrial rather than marine habitat during foraging trips was most affected by trip departure time relative to sunrise time, breeding stage, cloud cover and precipitation (d.f. $=6, \chi^{2}=282.1$, model 6 in Table 2, Fig. 3b). Terrestrial foraging predominated on foraging trips departing soon before or after sunrise $(\chi 2=138.7$, $p<0.001)$ and under cloudier $(\chi 2=7.601, p<0.01)$ conditions. Rainier $(\chi 2=3.355$, NS, $p=0.067)$ conditions may also favor terrestrial foraging, with inclusion of this term marginally lowering AICc (Table 2), but the term itself was not significant at $p<0.05$. Breeding stage was an important driver of foraging strategy, with fewer terrestrial trips occurring as the season progressed $\left(\chi^{2}=\right.$ 105.7, $p<0.001)$.

\section{Agricultural fields}

Data collected on agricultural fields is summarized in Additional file 7. Of the 10 models testing the effect of crop characteristics and time on lesser black-backed gull presence on agricultural fields, the model retaining vegetation height and observation period was the best fit (d.f. $=6, \chi^{2}=$ 
Table 2 Summary statistics for GLMMs to look at temporal and weather influences on the probability of lesser black-backed gulls $(n=14)$ to forage on terrestrial- over marine- habitat during foraging trips $(n=959)$, including the pre-laying period (April 30 - May 19) in 2012 and 2013. All models include individual gull ID as a random effect. Akaike information criterion adjusted for small sample sizes (AICc), change in AICc relative to the best-fit model (7) and marginal $R^{2}\left(R^{2} m\right)$ and conditional $R^{2}\left(R^{2} c\right)$ values are presented

\begin{tabular}{|c|c|c|c|c|c|c|}
\hline & Model & d.f. & $\mathrm{AlCc}$ & $\triangle \mathrm{AlCc}$ & $R^{2} m$ & $R^{2} C$ \\
\hline 1 & Intercept & 2 & 939.0 & 270.5 & - & 0.491 \\
\hline 2 & cloud + ppt + sunrise_prox & 5 & 768.6 & 100.0 & 0.162 & 0.664 \\
\hline 3 & cloud + temp + ppt + sunrise_prox & 6 & 677.3 & 8.745 & 0.311 & 0.692 \\
\hline 4 & cloud + temp + sunrise_prox & 5 & 677.0 & 8.411 & 0.308 & 0.691 \\
\hline 5 & stage + cloud + temp + sunrise_prox & 8 & 669.5 & 0.959 & 0.330 & 0.698 \\
\hline 6 & stage + cloud + ppt + sunrise_prox & 8 & 669.0 & 0.459 & 0.328 & 0.698 \\
\hline 7 & stage + cloud + temp + ppt + sunrise_prox & 9 & 668.6 & 0.000 & 0.336 & 0.699 \\
\hline
\end{tabular}

Variable names as in Table 1

Selected model (6) is indicated in bold

40.925, $p<0.001$, Fig. 5a, model 9 in Table 3). Gulls were more likely to be present on fields with low vegetation height $(x 2=10.81, p=0.001$, Fig. $5 b)$ and less likely to visit fields as the study period progressed $(\chi 2=7.4697, p<0.05$, Fig. 5c). The best fit model (model 9, Table 3) included both vegetation height and observation period, which had a lower AICc value than either model including only one of these two variables (models 7 and 8, Table 3). While median vegetation height did increase across observation periods, the variation in vegetation height was high within all periods, thus collinearity in the final model including both variables was not an issue $(\kappa<10)$. We tested for associations between lesser black-backed gulls and the number of other birds or earthworms by adding these variables to the best fit model (models 10, 11 and 12 in Table 3). Lesser black-backed gulls were positively associated with both waders $(x 2=4.9, p<0.05)$ and other gulls $(x 2=25.7, p<$ $0.001)$, but not with earthworms $(\chi 2=0.01, p>0.05)$.

\section{Discussion}

By tracking lesser black-backed gulls with GPS over three consecutive years together with observations on

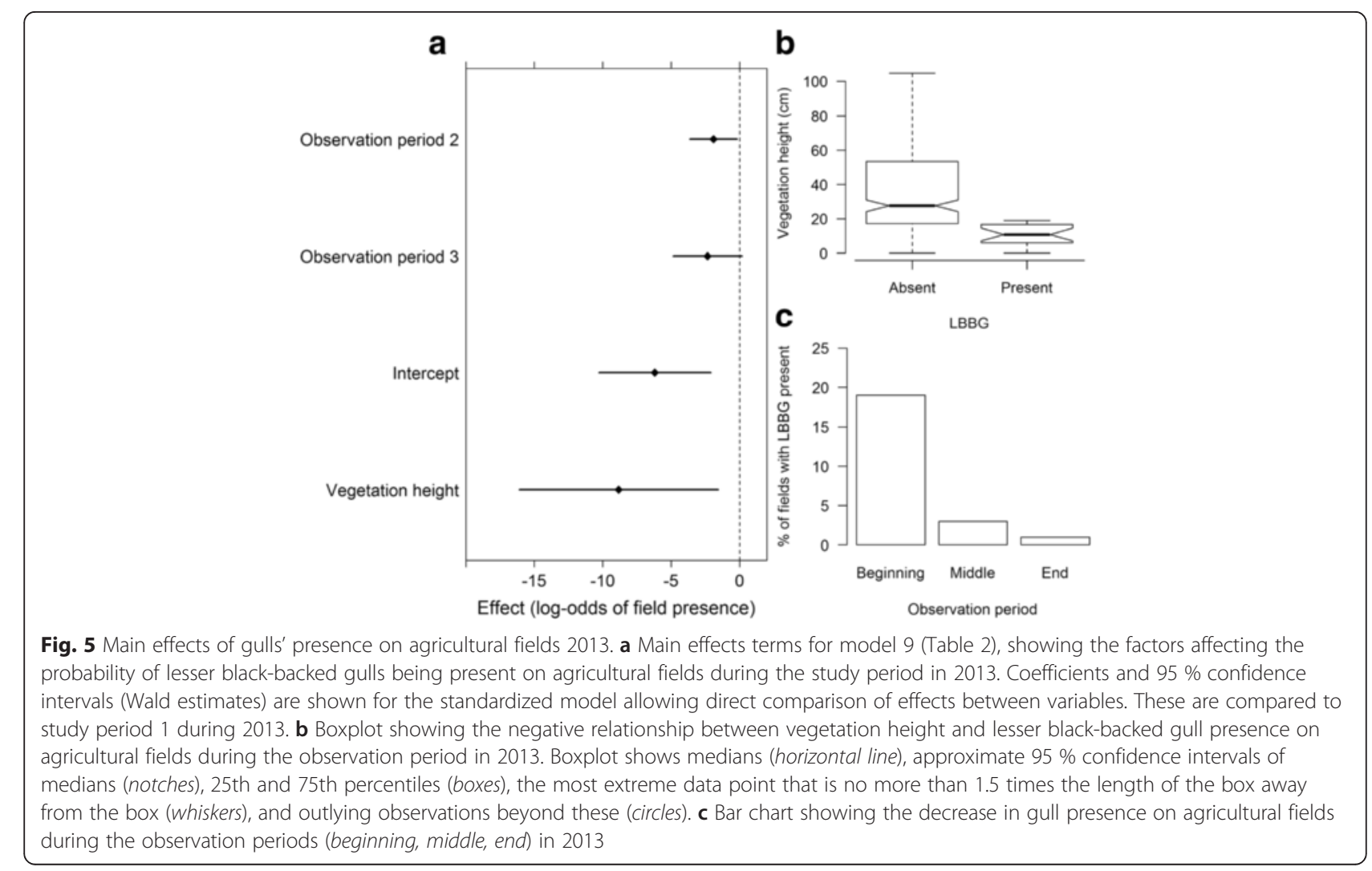


Table 3 Summary statistics for GLMMs to look at field characteristics and temporal influences on the probability of lesser black-backed gulls being present on agricultural fields (observations $=300, \mathrm{n}$ fields $=50, \mathrm{n}$ transects $=10$ ). We then tested for associations between lesser black-backed gulls and the number of birds of -other gull species (all gulls excluding lesser black-backed gulls), -waders (lapwings and oystercatchers), and the number of earthworms; by including these terms along with the best fit model (9). All models included field nested within transect as a random effect. Akaike information criterion adjusted for small sample sizes (AICC), change in AICc relative to the best-fit model (9) and marginal $R^{2}\left(R^{2} m\right)$ and conditional $R^{2}\left(R^{2} c\right)$ values are presented

\begin{tabular}{lllllll}
\hline & Model & d.f. & AICC & $\triangle A I C c$ & $R^{2} m$ & $R^{2} c$ \\
\hline 1 & day & 4 & 144.1 & 36.5 & 0.002 & 0.55 \\
2 & intercept & 3 & 142.3 & 34.7 & - & 0.54 \\
3 & crop + veg.height + veg.cover & 11 & 121.9 & 14.4 & 0.82 & 0.95 \\
4 & crop + veg.height & 8 & 118.1 & 10.5 & 0.86 & 0.95 \\
5 & obs.per + day & 6 & 117.9 & 10.3 & 0.11 & 0.92 \\
6 & veg.height + veg.cover & 7 & 117.1 & 9.52 & 0.83 & 0.94 \\
7 & obs.per & 5 & 116.3 & 8.73 & 0.11 & 0.92 \\
8 & veg.height & 4 & 110.9 & 3.32 & 0.83 & 0.94 \\
9 & veg.height + obs.per & $\mathbf{6}$ & $\mathbf{1 0 7 . 6}$ & $\mathbf{0 . 0 0}$ & $\mathbf{0 . 7 4}$ & $\mathbf{0 . 8 9}$ \\
10 & model 9+ earthworm & 4 & 109.7 & 2.09 & 0.74 & 0.89 \\
11 & model 9+ waders & 4 & 104.8 & -2.80 & 0.77 & 0.88 \\
12 & model 9+ gulls & 4 & 83.9 & -23.6 & 0.77 & 0.96 \\
\hline
\end{tabular}

crop = crop type, day = morning/evening, earthworm = number of earthworms, gulls = number of other gulls, obs.per = observation period, veg.cover = vegetation cover, veg.height $=$ vegetation height, waders $=$ number of waders (lapwing and oystercatcher)

Selected model (9) is indicated in bold

agricultural fields we set out to elucidate how these gulls make foraging decisions during the breeding season. We found that: (1) $21.2 \%$ of foraging trips were terrestrial in nature, $9.0 \%$ were a mix of terrestrial and marine, and $68.5 \%$ were exclusively marine; most often gulls departed on terrestrial foraging trips shortly before sunrise, while marine foraging trips occurred throughout the day. A switch in foraging strategy likely occurred during incubation, from terrestrial to marine. (2) Gulls were more likely to forage on land during cloudy and cold conditions. (3) There was no difference between females and males in their land-based foraging behaviour. (4) However, there was evidence for individual differences and consistency in terrestrial foraging. (5) Gulls were attracted to agricultural fields with short vegetation, and there was a positive association with waders and other gull species when on those fields. (6) Lastly, the availability of fields with short vegetation decreased through the season.

During the pre-laying stage (Additional file 8: Figure S4), terrestrial foraging was very high ( $>50 \%$ of foraging trips). This level of terrestrial foraging during the breeding season contrasts with other populations of lesser black-backed gull in northern Europe, which forage more at sea (e.g. $[5,8,51])$. Precedents for this level of terrestrial foraging can however be found in L. f. graellsii (Brehm 1857, the western sub-species) populations from Britain $[23,26]$. A recent study employing GPS tracks of lesser black-backed gulls breeding in the North Sea also found increased use of terrestrial foraging sites [52]. However, none of these studies included data from the pre-laying stage. Our long term tracking enables us to explore changes in foraging behavior over all stages of the breeding season, including the pre-laying phase, which is often missed in short term tracking studies, providing new insight into seasonal transitions in foraging strategies. Whether this is a pattern which was missed in previous studies due to lack of higher resolution data or shows a real shift in this species' behavior as a response to changes in either the terrestrial or marine environments remains to be seen.

The peak departure time for terrestrial foraging trips, the $2-3 \mathrm{~h}$ before sunrise and the first hour after sunrise (Fig. $4 \mathrm{~b}$ ), reflect the expected activity patterns of soil invertebrates [28] and corroborate that the gulls are sensitive to time-dependent prey availability $[6,53]$. Terrestrial foraging decreased as the breeding season progressed (Fig. 4 a, Additional file 8), corroborating evidence from other lesser black-backed gull studies which show dietary switching, from terrestrial to marine food sources, in conjunction with the onset of chick rearing [22-24]. Earlier in the season (i.e. May) breeding adults are in the egg-laying and incubation phases and thus may be selecting for food that is more predictable in time and space than marine prey $[22,53]$. Later in the season the chicks may need to be fed on high energy content and easily digestible food items, which marine fish are more likely to be than terrestrial invertebrates [15, 23-25]. It has previously been found that intrinsic factors such as breeding stage are the main cause of behavioral changes in foraging [54]. Frequency of mowing and sowing on agricultural fields during the early part of the breeding season, activities with which birds are associated [27, 29], may also play a part. Finally, travel costs may influence the gulls' foraging location choice $[40,55,56]$. Though the median maximum foraging trip distance for land was shorter than that for sea trips $(20.8 \mathrm{~km}$ versus $23.2 \mathrm{~km})$, terrestrial foraging trips were of longer duration than those to sea ( $6.2 \mathrm{~h}$ versus $3.9 \mathrm{~h}$ ). This suggests that while foraging areas on land might be closer to the colony, foraging there takes longer, resulting in a potential trade-off between travel cost and foraging efficiency which contrast between foraging on land or sea. Gulls foraging on land may also spend more time resting, thus contributing to longer durations of terrestrial trips.

Terrestrial foraging trips occurred more frequently when there was greater cloud cover, rainier conditions, 
and lower air temperatures. Cold and wet conditions have previously been associated with greater soil invertebrate activity [28] as well as with more terrestrial feeding by Hartlaub's gulls L. hartlaubii (Bruch 1853) and common gulls $[57,58]$. Unexpectedly, wind did not have a significant effect on foraging area choice, despite wind being a key driver of movement ecology in seabirds [59, 60]. In the study area south-westerly winds predominate, thus gulls may give little weight to wind conditions when making foraging decisions at this colony.

Previous studies on lesser black-backed gulls have found sexual segregation in foraging behavior [7] during incubation and chick rearing, which has also been described in other seabirds such as Northern gannet Morus bassanus [61], Audouin's gull L. audouinii [15] and herring gull [62]. We expected that females would forage more frequently on land than males, either due to sexspecific nutrient requirements or risk partitioning [30, 31]; however, we found no such difference (Additional file 6). A recent study on Ring-billed gull $L$. delawarensis (Ord 1815) also did not find sexual segregation in foraging behavior [63]. It could be that during incubation both sexes are foraging more frequently on land because the resources there are more predictable than at sea, thus following a risk-adverse strategy $[7,22,53]$.

Individual gulls differed consistently in their propensity to perform terrestrial over marine foraging trips with individual repeatability very high. This is consistent with findings in previous studies on individual specialization in foraging lesser black-backed gulls $[7,20]$ and has also been documented in herring and Western gulls $[64,65]$. Individual specialization in this population might come about through differences in body morphology, experience, and personality. An ultimate explanation may be that variation reduces intra-specific competition for resources and, especially during the breeding season, may increase individual reproductive success through risk partitioning [66]. Our findings potentially suggest that population level generalism in this species may arise through varying levels of individual specialization on different food sources, rather than all individuals being broadly generalists [67].

In addition to the GPS tracking data, our observations on agricultural fields in 2013 revealed that lesser blackbacked gulls were present on fields with vegetation shorter than ca. $20 \mathrm{~cm}$ (Fig. 5 b). This is consistent with their morphology, as gulls need to be able to walk and see sufficiently in order to forage on fields and this becomes more difficult with higher vegetation [27, 63]. While there was no significant association between earthworms and lesser black-backed gulls it is important to note that the gulls could be foraging more on other invertebrates (e.g., beetles), plant material, or even small mammals, all of which have been found to be important food sources in these gulls $[10,21,26,68]$. The significant positive relationship between lesser black-backed gulls and other species of gulls and waders suggests that one group (e.g., lapwings, black-headed gulls) could be attracting the others and therefore operating as an indicator [69] or that several gull species favor the same terrestrial foraging conditions [5], explanations which are not mutually exclusive. Of all the temporal variables, only observation period was relevant to lesser black-backed gull presence on agricultural fields (model 7, Table 3), with progressively fewer gulls present later in the season (Fig. 5c). The presence of observation period in the best fit model supports the hypothesis of dietary switching in lesser black-backed gull, especially when the pre-laying period is taken into account (Fig. 4a).

The lesser black-backed gull population on Stora Karlsö has had low breeding success since the mid2000 's $[11,70]$, with the reasons behind this unclear. While we may expect generalists to do well, it is possible that due to specializations, parts of the population may suffer under specific changes. A decline in the population of glaucous-winged gulls $L$. glaucescens has for instance been attributed to a switch in diet from marine to terrestrial food sources [15], while conversely yellowlegged gulls $L$. michahellis have benefited from a greater availability of anthropogenic food sources [14]. In light of the importance of terrestrial foraging to this population early in the breeding season, some explanatory factors may be suggested. It may be that anthropogenic activity on agricultural fields in May influences either the quantity or quality of foraging opportunities. Previous studies show that Larus gulls are sensitive to spatial and temporal variation in human food resource availability [6, 20,53]. For gulls, it has been proposed that food foraged on land is of lower quality than that foraged at sea (Nina O'Hanlon., unpublished data; [7]), so while it may be more predictable it is essentially 'junk food' that may lower breeding success by decreasing parental body condition. It is noteworthy that terrestrial foraging was highest during the pre-laying period (Fig. 4a), where diet is known to be critical to egg-building in lesser blackbacked gulls [30]. The heavy use of terrestrial resources early in the season might also reflect low marine prey quality and/or quantity in the area $[17,18]$. Coupled with likely competition with other seabirds at the colony (e.g. common murres and razorbills) that are provisioning chicks with the same prey during this time [19] it may be reasonable to predict that foraging success is too low to provision chicks adequately when the gulls do switch to marine prey. Therefore, terrestrial foraging at this colony may be a symptom of a greater regime shift in the ecosystem, which could help explain low breeding success. Further research and data on individual breeding success would be needed to tease apart these relationships, however. 


\section{Conclusions}

We combined the GPS-tracking of individual gulls with 'ground-truthing' of habitat visited to elucidate the otherwise nebulous foraging behavior of a generalist predator, the lesser black-backed gull. Our results demonstrate the high prevalence of terrestrial foraging during the early part of the breeding period, with marine foraging most prevalent later in the season. Individual gulls were consistent in their preference for marine or terrestrial foraging suggesting individual specialization. Within a day gulls were more likely to forage on land early in the morning and under cloudy and cold conditions; conditions and a time when prey such as earthworms are most likely to be available on the agricultural fields which the gulls use when on land. Gulls had a preference for fields with low vegetation, which are less available later in the season. That gulls varied their tendency for terrestrial foraging both within days and across the season suggests sophisticated dietary switching driven by some combination of internal state (e.g. breeding stage) and external factors (e.g. weather, time of day, and changes in habitat). This population of gulls has had low breeding success for a number of years; thus our results suggest that this may, in part, be due to variation in quantity and/or quality of anthropogenic terrestrial food sources. Overall the study demonstrates the power of combining individual tracking with 'groundtruthing' when studying the foraging behavior of generalist predators.

\section{Availability of supporting data}

The data sets supporting the results of this article are included within the article (and its additional files).

\section{Additional files}

Additional file 1: Table of lesser black-backed gulls GPS deployments (.doc). GPS deployments on lesser black-backed gulls at Stora Karlsö (2011-2013) with number of foraging trips per individual per year included in analysis. (PDF $125 \mathrm{~kb}$ )

Additional file 2: Detailed analytical methods on the processing of the GPS tracking data of the lesser black-backed gulls (.pdf). Information on which trips were included from the wider GPS tracking dataset and how activity within trips was classified between land and sea foraging is provided. (PDF $304 \mathrm{~kb}$ )

Additional file 3: Table of analyzed GPS data (.x|s). Foraging trips of lesser black-backed gulls, tracked by GPS. The analyzed data are provided as an Excel file, with two sheets, 'GPS_foraging_trip_data' giving the analyzed variables, and 'Metadata' explaining these variables. (XLSX $384 \mathrm{~kb}$ )

Additional file 4: Table of transect locations (.x/s). Locations of transects and fields surveyed in on-site portion of the study (May-June 2013). (XLSX $11 \mathrm{~kb}$ )

Additional file 5: Map of all GPS tracked gulls' locations (.pdf). (PDF $7882 \mathrm{~kb}$ )

Additional file 6: Random effect of the tracked gull individuals for model 18 in Table 1 (.pdf). (PDF 134 kb)
Additional file 7: Agricultural field parameters (.xIs). Vegetation parameters of the agricultural fields surveyed in on-site portion of the study, along with L. fuscus presence/absence counts, earthworm, other gull species and wader numbers throughout the study period (May-June 2013). (XLSX $17 \mathrm{~kb}$ )

Additional file 8: Proportion of land or sea or mixed foraging trips by GPS tracked gulls divided by year (.pdf). An extended version of Fig. 4 a. (PDF $850 \mathrm{~kb}$ )

\section{Competing interests}

The authors declare that they have no competing interests.

\section{Authors' contributions}

$\mathrm{NI}$ designed the study, carried out the field work, participated in the statistical analysis and co-drafted the manuscript. TJE helped design the study, participated in the field work, performed statistical analysis, and co-drafted the manuscript. JS-B helped draft the manuscript. SA conceived of the study, participated in its design and coordination and helped to draft the manuscript. All authors read and approved the final manuscript.

\section{Acknowledgements}

The study was financed by grants to SA from the Swedish Research Council (621-2007-5930; 621-2010-5584, 621-2013-4361) with support from the Centre for Animal Movement Research (CAnMove) funded by a Linnaeus grant from the Swedish Research Council (349-2007-8690) and Lund University. The work was approved by the ethical committee for research with wild animals (Malmö/Lunds Djurförsöksetiska nämnd; permission number: M113-09), and for work within a protected area by the County Administrative Board (Länsstyrelsen, Gotland). NCEP Reanalysis 2 data provided by the NOAA/OAR/ESRL PSD, Boulder, Colorado, USA, from their Web site at http://www.esrl.noaa.gov/psd/. We thank the Baltic Seabird Project and Karlsö Jagt-och Djurskyddsförening AB for their cooperation and aid with field work at Stora Karlsö. We thank Arne Andersson, Johan Bäckman (both CAnMove, Lund University), Edwin Baaij, Willem Bouten (UVA-BiTS, Amsterdam University), Juliana Dänhardt, Tina D'Hertefeldt, Ola Olsson, and Martin Stjernman (Department of Biology, Lund University) for support and advice. We thank two anonymous reviewers for thoughtful and insightful comments and suggestions.

\section{Author details}

${ }^{1}$ Centre for Animal Movement Research, Department of Biology, Ecology Building, Lund University, Lund SE-223 62, Sweden. ${ }^{2}$ Computational Geo-Ecology, University of Amsterdam, Postbus 94248, Amsterdam 1090 GE, The Netherlands.

Received: 8 December 2015 Accepted: 4 April 2016

Published online: 15 May 2016

\section{References}

1. Nathan R, Getz WM, Revilla E, Holyoak M, Kadmon R, Saltz D, Smouse PE. A movement ecology paradigm for unifying organismal movement research. Proc Natl Acad Sci U S A. 2008;105:19052-9.

2. Perry G, Pianka ER. Animal foraging: past, present and future. Trends Ecol Evol. 1997;12:360-4.

3. Drent $\mathrm{RH}$, Daan $\mathrm{S}$. The prudent parent: energetic adjustments in avian breeding. Ardea. 1980;68:225-52.

4. Soanes LM, Arnould JPY, Dodd SG, Milligan G, Green JA. Factors affecting the foraging behaviour of the European shag: implications for seabird tracking studies. Mar Biol. 2014;161:1335-48.

5. Schwemmer P, Garthe S, Mundry R. Area utilization of gulls in a coastal farmland landscape: habitat mosaic supports niche segregation of opportunistic species. Landscape Ecol. 2008;23:355-67.

6. Yoda K, Tomita N, Mizutani Y, Narita A, Niizuma Y. Spatio-temporal responses of black-tailed gulls to natural and anthropogenic food resources. Mar Ecol Prog Ser. 2012:466:249-59.

7. Camphuysen KCJ, Shamoun-Baranes J, van Loon EE, Bouten W. Sexually distinct foraging strategies in an omnivorous seabird. Mar Biol. 2015;162: 1417-28. 
8. Strann K, Vader W. The nominate lesser black-backed gull Larus fuscus fuscus, a gull with a tern-like feeding biology, and its recent decrease in northern Norway. Ardea. 1992;80:133-42.

9. Kubetzki U, Garthe S. Distribution, diet and habitat selection by four sympatrically breeding gull species in the south-eastern North Sea. Mar Biol. 2003;143:199-207.

10. Götmark F. Food and foraging in five European Larus gulls in the breeding season: a comparative review. Ornis Fennica. 1984;61:9-18.

11. Lif M, Hjernqvist M, Olsson O, Österblom H. Long-term population trends in the Lesser Black-backed Gull Larus f. fuscus at Stora Karlsö and Lilla Karlsö, and initial results on breeding success. Ornis Svec. 2005;15:105-12.

12. ArtDatabanken: Rödlistade arter i Sverige 2015. ArtDatabanken SLU, Uppsala. 2015. http://www.artdatabanken.se/media/2013/hela-boken.pdf Accessed 2 Dec 2015.

13. Alm DS. Elevated adult mortality in Larus gulls of the Baltic Sea - analyses with an ecosystem change approach. Sweden: Degree thesis, Stockholm University; 2006

14. Duhem C, Roche P, Vidal E, Tatoni T. Effects of anthropogenic food resources on yellow-legged gull colony size on Mediterranean islands. Popul Ecol. 2008;50:91-100.

15. Navarro J, Oro D, Bertolero A, Genovart M, Delgado A, Forero MG. Age and sexual differences in the exploitation of two anthropogenic food resources for an opportunistic seabird. Mar Biol. 2010;157:2453-9.

16. Blight LK, Hobson KA, Kyser TK, Arcese P. Changing gull diet in a changing world: A 150-year stable isotope $(\delta 13 \mathrm{C}, \delta 15 \mathrm{~N})$ record from feathers collected in the Pacific Northwest of North America. Glob Change Biol. 2015;21:1497-507.

17. Möllmann C, Diekmann R, Müller-Karulis B, Kornilovs G, Plikshs M, Axe P. Reorganization of a large marine ecosystem due to atmospheric and anthropogenic pressure: a discontinuous regime shift in the Central Baltic Sea. Glob Change Biol. 2009;15:1377-93.

18. Casini M, Lövgren J, Hjelm J, Cardinale M, Molinero JC, Kornilovs G. Multilevel trophic cascades in a heavily exploited open marine ecosystem. P Roy Soc Lond B Bio. 2008;275:1793-801.

19. Kadin M, Olsson O, Hentati-Sundberg J, Willerström Ehrning E, Blenckner T. Common Guillemot Uria aalge parents adjust provisioning rates to compensate for low food quality. Ibis. 2016;158:167-78.

20. Tyson C, Shamoun-Baranes J, Loon EEV, Camphuysen K, Hintzen NT. Individual specialization on fishery discards by lesser black-backed gulls (Larus fuscus). ICES J Mar Sci. 2015;72:1882-91.

21. Kim S-Y, Monaghan P. Interspecific differences in foraging preferences, breeding performance and demography in herring (Larus argentatus) and lesser blackbacked gulls (Larus fuscus) at a mixed colony. J Zool. 2006;270:664-71.

22. Annett CA, Pierotti R. Chick hatching as trigger for dietary switching in the Western gull. Colonial Waterbirds. 1989;12:4-11.

23. Perrins CM, Smith SB. The breeding Larus gulls on Skomer island national nature reserve. Pembrokeshire Atlantic Seabirds. 2000;2:195-210.

24. Camphuysen CJ. A historical ecology of two closely related gull species (Laridae): multiple adaptations to a man-made environment. Groningen: Ph D. thesis, University of Groningen; 2013.

25. Tasker ML, Camphuysen CJ, Fossum P. Variation in prey taken by seabirds. In: Furness RW, Tasker ML, editors. Diets of seabirds and consequences of changes in food supply. ICES Coop. Res. Report No. 232, International Council for the Exploration of the Sea, Copenhagen. 1999. p.18-28.

26. Coulson JC, Coulson BA. Lesser Black-Backed Gulls Larus fuscus nesting in an inland urban colony: the importance of earthworms (Lumbricidae) in their diet. Bird Study. 2008;55:297-303.

27. Buckley PA, McCarthy MG. Insects, vegetation, and the control of laughing gulls (Larus atricilla) at Kennedy International Airport, New York City. J Appl Ecol. 1994;31:291-302.

28. Kruuk H. Foraging and spatial organization of the European badger, Meles meles L. Behavioral Ecol Sociobiol. 1978:4:75-89.

29. Devereaux CL, Whittingham MJ, Krebs JR, Fernandez-Juricic E, Vickery JA. What attracts birds to newly mown pasture? Decoupling the action of mowing from the provision of short swards. Ibis. 2006;146:302-6.

30. Blount JD, Houston DC, Surai PF, Møller AP. Egg-laying capacity is limited by carotenoid pigment availability in wild gulls Larus fuscus. P Roy Soc Lond B Bio. 2004;271:79-81.

31. Elliott KH, Gaston AJ, Crump D. Sex-specific behavior by a monomorphic seabird represents risk partitioning. Behav Ecol. 2010; doi:10.1093/beheco/arq076.
32. Hentati-Sundberg J, Österblom H, Kadin M, Jansson $\AA$, Olsson O. The Karlsö murre lab methodology can stimulate innovative seabird research. Marine Ornithol. 2012;40:11-6.

33. Bouten W, Baaij EW, Shamoun-Baranes J, Camphuysen KCJ. A flexible GPS Tracking system for studying bird behavior at multiple scales. J Ornithol. 2013;154:571-80.

34. Thaxter CB, Ross-Smith VH, Clark JA, Clark NA, Conway GJ, Marsh M, et al. A trial of three harness attachment methods and their suitability for long-term use on Lesser Black-backed Gulls and Great Skuas. Ringing Migr. 2014;29:65-76.

35. Coulson JC, Thomas CS, Butterfield JEL, Duncan N, Monaghan P, Shedden C. The use of head and bill length to sex live gulls Laridae. Ibis. 1983;125:549-57.

36. Kanamitsu M, Ebisuzaki W, Woollen J, Yang S-K, Hnilo JJ, Fiorino M, et al. NCEP-DOE AMIP-II Reanalysis (R-2). B Am Meteorol Soc. 2002;1631-1643.

37. R Core Team R: A Language and Environment for Statistical Computing. $R$ Foundation for Statistical Computing, Vienna, Austria. ISBN 3-900051-07-0. 2013. http://www.R-project.org/

38. Kemp MU, van Loon E, Shamoun-Baranes J, Bouten W. RNCEP: global weather and climate data at your fingertips. Methods Ecol Evol. 2012;3:65-70.

39. Bivand R, Lewin-Koh N, Pebesma E, Archer E, Baddeley A, Bearman N, et al. Tools for reading and handling spatial objects. 2015. http://r-forge.r-project. org/projects/maptools/

40. Elliott KH, Chivers LS, Bessey L, Gaston AJ, Hatch SA, Kato A, et al. Windscapes shape seabird instantaneous energy costs but adult behavior buffers impact on offspring. Mov Ecol. 2014;2:17.

41. Dänhardt J. On the importance of farmland as stopover habitat for migrating birds. Ph.D. thesis, Lund University, Lund. 2009.

42. Bates D, Maechler M, Bolker B, Walker S. Lme4: Linear mixed-effects models using Eigen and S4. R package version 1.0-6. 2014. https://cran.rproject.org/ web/packages/Ime4/index.html. Accessed 7 April 2016.

43. Burnham KP, Anderson DR. Model selection and multimodel inference: a practical information-theoretic approach. 2nd ed. New York: Springer; 2002.

44. Nakagawa S, Schielzeth $H$. A general and simple method for obtaining $R^{2}$ from generalized linear mixed-effects models. Methods Ecol Evol. 2013;4:133-42.

45. Barton K. MuMIn: Multi-model inference. R package version 1.10.0. 2014. https://cran.rproject.org/web/packages/MuMIn/index.html. Accessed 7 April 2016.

46. Gelman A. Scaling regression inputs by dividing by two standard deviations. Stat Med. 2008;27:2865-73.

47. Gelman A, Su YS, Yajima M, Hill J, Pittau MG, Kerman J, et al. arm: Data Analysis Using Regression and Multilevel/Hierarchical Models. 2015. https:// cran.r-project.org/web/packages/arm/index.htmle. Accessed 7 April 2016.

48. Baayen $\mathrm{RH}$. Analyzing linguistic data: A practical introduction to statistics using R. Cambridge: Cambridge University Press; 2008

49. Nakagawa S, Schielzeth H. Repeatability for Gaussian and non-Gaussian data: a practical guide for biologists. Biol Rev. 2010;85:935-56.

50. Garamszegi LZ. Uncertainties due to within-species variation in comparative Studies: measurement errors and statistical weights. In: Garamszegi LZ, editor. Modern phylogenetic comparative methods and their application in evolutionary biology. Berlin: Springer; 2014. p. 157-99.

51. Hario M. Breeding failure and feeding conditions of lesser black-backed gulls Larus f. fuscus in the Gulf of Finland. Ornis Fennica. 1990;67:113-29.

52. Corman AM, Mendel B, Voigt CC, Garthe S. Varying foraging patterns in response to competition? A multicolony approach in a generalist seabird. Ecol Evol. 2016; doi:10.1002/ece3.1884

53. Cama A, Abellana R, Christel I, Ferrer X, Vieites DR. Living on predictability: modelling the density distribution of efficient foraging seabirds. Ecography. 2012;35:912-21.

54. Humphreys EM, Wanless S, Bryant DM. Stage-dependent foraging in breeding black-legged kittiwakes Rissa tridactyla: distinguishing behavioural responses to intrinsic and extrinsic factors. J Avian Biol. 2006:37:436-46

55. Bernstein C, Kacelnik A, Krebs JR. Individual decisions and the distribution of predators in a patchy environment. II. The influence of travel costs and structure of the environment. J Anim Ecol. 1991;60:205-25.

56. Shamoun-Baranes J, van Loon E. Energetic influence on gull flight strategy selection. J Exp Biol. 2006;209:3489-98.

57. Vernon JDR. Food of the common gull on grassland in autumn and winter. Bird Study. 1970;17:36-8.

58. Steele WK. Factors influencing inland foraging by gulls. The Ostrich. 1989;60: $45-7$. 
59. Spear LB, Ainley DG. Flight behavior of seabirds in relation to wind direction and wing morphology. Ibis. 1997;139:221-33.

60. Lewis S, Phillips RA, Burthe SJ, Wanless S, Daunt F. Contrasting responses of male and female foraging effort to year-round wind conditions. J Anim Ecol. 2015;84:1490-6.

61. Lewis S, Benvenuti S, Dall-Antonia L, Griffiths R, Money L, Sherratt TN, et al. Sex-specific foraging behavior in a monomorphic seabird. P Roy Soc Lond B Bio. 2002;269:1687-93.

62. Pons J. Feeding strategies of male and female herring gulls during the breeding season under various feeding conditions. Ethol Ecol Evol. 1994;6:1-12.

63. Patenaude-Monette M, Belisle M, Giroux J-F. Balancing energy budget in a central-place forager: which habitat to select in a heterogeneous environment? PLoS ONE. 2014; doi:10.1371/journal.pone.0102162

64. Pierotti $R$, Annett CA. Diet choice in the herring gull: constraints imposed by reproductive and ecological factors. Ecology. 1991;72:319-28.

65. Annett CA, Pierotti R. Long-term reproductive output in Western gulls: consequences of alternate tactics in diet choice. Ecology. 1999;80:288-97.

66. Bolnick DI, Svanbäck R, Fordyce JA, Yang LH, Davis JM, Hulsey CD, Forister $\mathrm{ML}$. The ecology of individuals: incidence and implications of individual specialization. Am Nat. 2003;161:1-28.

67. Vander Zanden HB, Bjorndal KA, Reich KJ, Bolten AB. Individual specialists in a generalist population: results from a long-term stable isotope series. Biol Lett. 2010;6:711-4

68. Camphuysen CJ, de Boer P, Bouten W, Gronert A, Shamoun-Baranes J. Mammalian prey in Laridae: increased predation pressure on mammal populations expected. Lutra. 2010;53:5-20.

69. Tremblay Y, Thiebault A, Mullers R, Pistorius P. Bird-borne video-cameras show that seabird movement patterns relate to previously unrevealed proximate environment, not prey. PLoS ONE. 2014; doi:10.1371/journal.pone. 0088424

70. Capandegui E. Factors influencing the breeding success of two ecologically similar gulls the lesser black-backed gull Larus f. fuscus and herring gull Larus argentatus at Stora Karlsö. Stockholm: Degree thesis, Stockholm University; 2006

71. Liebers D, Helbig AJ. Phylogeography and colonization history of Lesser Black-backed Gulls (Larus fuscus) as revealed by mtDNA sequences. J Evol Biol. 2002;15:1021-33.

\section{Submit your next manuscript to BioMed Central and we will help you at every step:}

- We accept pre-submission inquiries

- Our selector tool helps you to find the most relevant journal

- We provide round the clock customer support

- Convenient online submission

- Thorough peer review

- Inclusion in PubMed and all major indexing services

- Maximum visibility for your research

Submit your manuscript at www.biomedcentral.com/submit 